\title{
Serum Thymidine Kinase 1 as a Biomarker for Breast Benign and Malignant Tumor Risk Assessment: A Meta-Analysis
}

\author{
Hongbo Ma\#, Ailian Hei"*, Ji Zhou, Jin Li, Ellen He* and Sven Skog \\ Department of Medicine, Shenzhen Sino Swed Precision Medicine Institute, China \\ "These authors contributed equally \\ *Corresponding author: Ailian Hei, Department of Medicine, Shenzhen Sino Swed Precision Medicine Institute, China \\ *Ellen He, Department of Medicine, Shenzhen Sino Swed Precision Medicine Institute, China
}

\begin{tabular}{|c|}
\hline ARTICLE INFO \\
\hline Received: 蔧 August 23, 2020 \\
\hline Published: 慧 September 14,2020 \\
\hline
\end{tabular}

Citation: Hongbo Ma, Ailian Hei, Ji Zhou, Jin Li, Ellen He, Sven Skog. Serum Thymidine Kinase 1 as a Biomarker for Breast Benign And Malignant Tumor Risk Assessment: A Meta-Analysis. Biomed J Sci \& Tech Res 30(3)-2020. BJSTR. MS.ID.004943.

Keywords: Serum Thymidine Kinase 1; STK1p; Breast Benign and Malignant Tumor; Surgery Therapy

Abbreviations: MD: Mean Difference; CI: Confidence Interval; TK1: Thymidine Kinase 1; NOS: Newcastle-Ottawa Scale

\begin{abstract}
Objectives: Thymidine Kinase 1 (TK1) has been recognized as a biomarker for cell proliferation. Serum TK1 concentration (STK1p) is a useful indicator reflecting abnormal cell proliferation status of malignancy in human body. The purpose of this meta-analysis is to analyze the clinical values of STK1p in breast cancer and thus to provide new insights and tools for breast malignant tumor risk assessment and early detection.
\end{abstract}

Methods: Eligible publications were identified from PubMed, EMBASE, the Cochrane Library, CNKI, Wanfang, VIP and SinoMed databases from January 1, 2000 until July 31, 2020. The meta-analysis followed the PRISMA statement and was conducted using RevMan 5.3 and STATA 16.0 software.

Results: A total of 25 clinical studies were included in this meta-analysis, including 1,813 breast cancer patients, 812 benign breast disease patients and 970 healthy individuals. There were significant differences in the Mean Difference (MD) and 95\% Confidence Interval (CI) of STK1p values between healthy group and breast malignant group $[\mathrm{MD}=-1.94,95 \% \mathrm{CI}(-2.02 \sim-1.85), \mathrm{p}<0.00001]$, between benign disease group and breast malignant group [MD $=-1.70,95 \% \mathrm{CI}(-1.85 \sim-1.55), \mathrm{p}<0.00001]$, and between before and after treatment groups [MD $=0.98,95 \%$ CI $(0.44-1.52), \mathrm{p}=0.0004]$. The Egger's tests showed that there was no significant publication bias in all groups.

Conclusions: This meta-analysis indicated that the level of STK1p in breast malignant patients was significantly higher than that in benign disease group and the healthy control group. The level of STK1p in breast malignant patients decreased significantly after being treated with surgery. STK1p would be a useful biomarker for breast benign and malignant tumors risk assessment and treatment response assessment.

\section{Introduction}

Breast cancer is one of the most common malignant tumors in women, which is threatening women's health. According to the statistical data in 2012, there were 1.67 million new cases of female breast cancer, accounting for $25 \%$ of all female malignant tumors, and 521,900 deaths, accounting for $15 \%$ of all female malignant tumor deaths [1]. In China, the incidence of breast cancer is not optimistic. China cancer registry annual report shows that in 2012, the incidence rate of breast cancer was as high as $42.55 / 100,000$.
With the change of lifestyle, breast cancer has become the highest incidence rate in China, and showing a younger trend and a rising in mortality rapidly $[1,2]$. Thus, breast cancer has become a serious public health issue in China. It is crucial to explore highly sensitive and specific approaches, especially in non-invasive tumor-related biomarkers to achieve early malignancy risk detection and then offer patients a better chance of early treatment and cure. Biochemical and cell biology studies since 1950s shows that Thymidine Kinase 
1 (TK1) is a key enzyme involved in the pyrimidine salvage pathway playing an important role in DNA synthesis during S-phase of cell cycle [3]. TK1 has been used for assessment of tumor proliferation rate by serological methods, including TK activity and TK1 concentration (STK1p) assays, as well as histochemical staining in clinical setting $[4,5]$. Although serum thymidine kinase activity increases in malignant tumors, for example in breast cancer, it is not widely applied in routine clinical laboratories due to the nonspecificity substrate used in the TK activity assay.

On the other hand, the STK1p assay uses a specific chicken anti-human TK1 IgY polyclonal antibody raised against a peptide (residue 195-225, GQPAG PDNKE NCPVP GKPGE AVAAR KLFAPQ) in a commercial enhanced chemiluminescence dot blot immunoassay (www.sstk.biotech.com), frequently used in clinical studies of breast cancer patients. However, most of individual TK1 studies so far included a limited number of cases which may affect the reliability of the conclusions, and thus initiated the present meta-analysis. STK1p has a clinical significance in monitoring tumor therapy responses and prognosis in breast malignancies $[6,7]$. Clinical studies also demonstrated that the half-life of STK1p could be an important tool for evaluating the response to surgery in malignant patients, for example in lung and gastric malignancies $[8,9]$. Furthermore, the level of STK1p can be used as a prognostic factor to reflect the abnormal cell proliferation status of breast tumors in the human body and will be able to assess the risk of early tumor before visible tumor by image [10]. Regarding the diagnosis of breast cancer, pathological biopsy and imaging examination are important criteria for the confirmation of breast cancer, but such techniques cannot evaluate tumor growth rate. As a matter of fact, most patients are diagnosed at the middle or advanced stages, which has lost the optimal therapy period to cure or recover. STK1p has the potential to be a useful biomarker in early breast cancer risk assessment, treatment response monitoring and prognostic factor, as STK1p changes appear before tumors are visible on imaging.

Breast cancer is recognized as a group of biologically and molecularly heterogeneous diseases originated from the breast normal tissue [11]. The histologic grade is an important indicator of tumor aggressiveness that reflects three features including tubule formation, nuclear pleomorphism and mitotic index, which is directly related to proliferation [12]. Since STK1p expression is related to grade and stage in breast cancer [10], the STK1p as a proliferation biomarker could have implications for risk prediction of aggressive forms of breast tumors. The purpose of this study was to conduct a meta-analysis with respect to the clinical values of STK1p in distinguishing breast benign and malignant tumor risk and monitoring treatment responses based upon a sufficient number of cases, thus to provide new insights and tools for breast malignant tumor risk assessment and early detection. Of the 269 publications on TK1 in breast cancer patients, only 25 articles were collected in the final analysis.

\section{Materials and Methods}

\section{Literature Search}

A systematic search of published articles from PubMed, EMBASE, the Cochrane Library, CNKI, Wanfang, VIP and SinoMed databases from January 1, 2000 until July 31, 2020 was performed using the following strategy and keywords: ('thymidine kinase 1' or 'TK1') and (breast) and ('cancer' or 'tumor' or 'carcinoma' or 'malignancy').

\section{Inclusion Criteria}

The studies were screened, evaluated and selected by two separate reviewers strictly following the inclusion and exclusion criteria. The inclusion criteria were: (1) measuring the STK1 concentration; (2) using an enhanced chemiluminescence dot blot STK1 assay system (SSTK Ltd., Shenzhen, China); (3) following international standard guidelines to diagnose breast cancer; (4) containing STK1 concentration data with mean and standard deviation, or data that could be re-estimated; (5) including appropriate control groups such as healthy control, benign disease control, or before and after breast cancer treatment control.

\section{Exclusion Criteria}

The exclusion criteria in this study were: (1) review or editorial comments or case report; (2) insufficient data; (3) studies containing unqualified data; (5) lack of appropriate control groups.

\section{Data Extraction}

Two reviewers independently assessed the quality of studies using the Newcastle-Ottawa Scale (NOS). Studies with NOS scores more than 5 points were included in this meta-analysis. The full texts were carefully reviewed for each collected article. Then, the following data were extracted from each study: first author's name, publication year, the article title, journal, study population characteristics (design type, number of subjects, sources of control, age), specimen type, and testing results. The meta-analysis followed the PRISMA guidelines. Since all analyses were based upon published literature, no ethical approval and patient consent were required.

\section{Statistical Analysis}

The meta-analysis was performed with RevMan 5.3 software provided by the Networks of Cochrane Review Groups and STATA 16.0 software (Stata Corporation, College Station, TX, USA). Initially, a heterogeneity test was conducted at the beginning. Then, the weighted Mean Difference (MD) and 95\% Confidence Interval (CI) was calculated using a fixed-effect model or a random-effect model based on the heterogeneity results. A fixed-effect model was selected when the $\mathrm{I}^{2}$ was lower than $50 \%$ and $\mathrm{p}$-value was $>0.05$. Otherwise, a random-effect model was used when the $\mathrm{I}^{2}$ was greater 
than $50 \%$ and p-value was $<0.05$. Moreover, sensitivity analyses were performed with STATA 16.0 software to evaluate the effects of excluding any individual study. Finally, Egger's tests were used to examine publication bias. A p-value of $<0.05$ was considered to indicate significance.

\section{Results}

\section{Literature Search and Study Characteristics}

Figure 1 shows the process of literature retrieval and study selection. Initially, 269 publications were identified from various databases. A total of 78 articles remained after reviewing the title and abstract of each publication. Then, 53 articles were excluded from the remaining 78 articles since 24 articles used other STK1 detection methods which did not meet the inclusion requirements of this study; 17 articles lacked complete data for conducting this meta-analysis; 12 review articles were also excluded due to be unqualified for meta-analysis. As a result, 25 articles were included in the final analysis [13-37]. The main clinical characteristics of each included study were extracted and summarized in Table 1. From the 25 studies between 2010 and 2020, a total of 1,813 breast cancer patients, 970 healthy individuals and 812 benign breast disease patients were included in this meta-analysis. All cancer cases in the study were diagnosed by a pathological examination according to clinical practice guidelines. In this study, the age ranged approximately from 16 to 82 among the breast patient population.

Table 1: Summary of the clinical data from each included publication.

\begin{tabular}{|c|c|c|c|c|c|c|c|c|c|c|c|}
\hline \multirow{2}{*}{$\begin{array}{l}\text { Author and } \\
\text { issuing time }\end{array}$} & \multirow{2}{*}{ Location } & \multirow{2}{*}{$\begin{array}{l}\text { Control } \\
\text { (n) }\end{array}$} & \multirow{2}{*}{$\begin{array}{c}\text { Benign } \\
\text { (n) }\end{array}$} & \multirow{2}{*}{$\begin{array}{c}\text { Breast } \\
\text { Cancer (n) }\end{array}$} & \multirow{2}{*}{ Age } & \multirow{2}{*}{$\begin{array}{c}\text { TNM } \\
\text { staging }\end{array}$} & \multicolumn{3}{|c|}{ Clinical stage (n) } & \multicolumn{2}{|c|}{ Surgery treatment } \\
\hline & & & & & & & $\mathbf{0}$ & I+II & III+IV & Before (n) & After (n) \\
\hline Chen QB et al. [16] & South China & 20 & - & 30 & $38-70$ & $\mathrm{Y}$ & - & 16 & 14 & 30 & 30 \\
\hline Duan CX et al. [22] & North China & 80 & 80 & 100 & $21-79$ & $\mathrm{Y}$ & 24 & 55 & 21 & - & - \\
\hline Fang K et al. [31] & East China & - & 68 & 112 & $16-79$ & $\mathrm{Y}$ & - & 80 & 10 & - & - \\
\hline Guan H, [14] & South China & - & 42 & 72 & $30-75$ & $\mathrm{Y}$ & - & 40 & 32 & - & - \\
\hline Hao WM et al. [27] & East China & 30 & 30 & 36 & $21-70$ & $\mathrm{Y}$ & - & 20 & 16 & - & - \\
\hline Hou H et al. [28] & East China & - & 30 & 62 & $16-79$ & $\mathrm{~N}$ & - & - & - & - & - \\
\hline Huang H et al. [15] & South China & 30 & 30 & 100 & - & $\mathrm{Y}$ & 20 & 55 & 25 & - & - \\
\hline Huang J et al. [23] & South China & 33 & - & 65 & $19-63$ & $\mathrm{Y}$ & - & 29 & 36 & 38 & 38 \\
\hline $\begin{array}{c}\text { Jiang AK et al., } \\
{[35]}\end{array}$ & South West & 125 & - & 125 & $25-69$ & $\mathrm{Y}$ & - & 110 & 15 & 125 & 125 \\
\hline Jiang MJ et al. [19] & East China & 50 & 66 & 73 & $29-78$ & $\mathrm{~N}$ & - & - & - & - & - \\
\hline Li B et al. [17] & East China & 35 & 40 & 90 & $22-80$ & $\mathrm{Y}$ & 20 & 50 & 20 & - & - \\
\hline Li XF et al. [30] & East China & 50 & 66 & 92 & - & $\mathrm{Y}$ & 19 & 57 & 16 & - & - \\
\hline Li XQ et al. [29] & East China & 50 & - & 42 & $26-82$ & $\mathrm{Y}$ & - & 28 & 14 & - & - \\
\hline Liao HY et al. [24] & East China & 42 & 50 & 90 & $24-76$ & $\mathrm{Y}$ & - & 43 & 47 & 90 & 90 \\
\hline Nong L et al. [36] & South China & - & - & 31 & $29-71$ & $\mathrm{Y}$ & - & - & 31 & - & - \\
\hline Qin ZL et al. [32] & South China & 100 & - & 104 & $39-66$ & $\mathrm{Y}$ & - & 71 & 33 & - & - \\
\hline Ren RB et al. [25] & East China & - & 55 & 145 & $21-79$ & $\mathrm{Y}$ & - & 68 & 40 & - & - \\
\hline Shan Z et al [20] & East China & 50 & 90 & 30 & $33-72$ & $\mathrm{~N}$ & - & - & - & - & - \\
\hline Shen LL et al. [34] & East China & - & 48 & 48 & $24-75$ & $\mathrm{~N}$ & - & - & - & - & - \\
\hline Tao XJ et al. [18] & East China & 48 & 52 & 69 & $32-59$ & $\mathrm{Y}$ & - & 33 & 36 & - & - \\
\hline Xie GQ et al. [21] & East China & 32 & 35 & 34 & $37-76$ & $\mathrm{~N}$ & - & - & - & 34 & 34 \\
\hline Yuan ZY et al. [13] & East China & 14 & - & 48 & 29-77 & $\mathrm{Y}$ & - & 26 & 22 & 14 & 14 \\
\hline Zhang HZ, [33] & East China & - & - & 80 & - & $\mathrm{N}$ & - & - & - & - & - \\
\hline Zhang LJ et al. [37] & South West & 20 & 30 & 70 & $>20$ & $\mathrm{Y}$ & - & 49 & 21 & - & - \\
\hline Zhang ZJ et al. [26] & East China & 161 & - & 65 & $19-63$ & $\mathrm{~N}$ & - & - & - & - & - \\
\hline Total number & & 970 & 812 & 1813 & & & 83 & 830 & 449 & 331 & 331 \\
\hline
\end{tabular}

$\mathrm{Y}=$ Yes; $\mathrm{N}=\mathrm{No}$ 


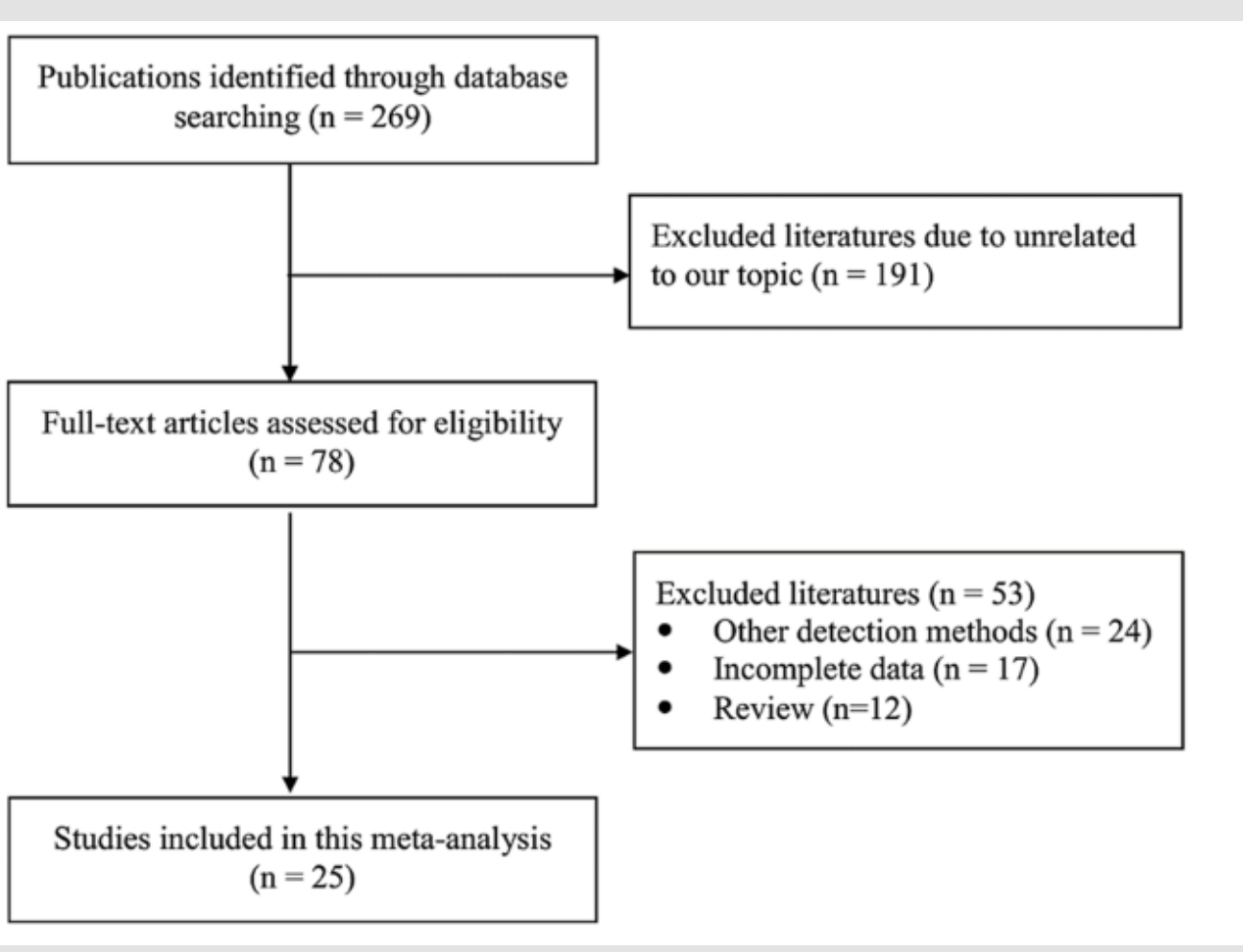

Figure 1: Flow chart of literature selection for the meta-analysis.

STK1p Level of Breast Malignant Patients Compared to Healthy Control Group

Of the 25 studies included in this meta-study, 18 were used for comparison analysis between breast malignant patients and healthy subjects (Figures 2A \& 3A). The number of breast malignant patients and number of cases of healthy subject was 1,263 and 970, respectively. There were significant differences between the two groups after the heterogeneity test $(\mathrm{p}<0.00001$, $\left.I^{2}=97 \%\right)$. Therefore, the effect of the merging was carried out using a random-effect model. The results showed that the weighted Mean Difference (MD) between the two groups was statistically significant at the 0.05 level (MD $=-1.94,95 \%$ CI $(-2.02 \sim-1.85)$, $\mathrm{p}<0.00001)$. The level of STK1p among breast malignant patients $(3.00 \pm 2.19 \mathrm{pM})$ was significantly higher than that among healthy subjects $(0.58 \pm 0.37 \mathrm{pM})$ (Figure $3 \mathrm{~A})$.

\begin{tabular}{|c|c|c|c|c|c|c|c|c|c|c|c|c|}
\hline \multirow[b]{2}{*}{ Study or Subqroup } & \multicolumn{3}{|c|}{ Healthy } & \multicolumn{3}{|c|}{ Malignant } & \multicolumn{2}{|r|}{ Mean Difference } & & \multirow{2}{*}{\multicolumn{2}{|c|}{$\begin{array}{l}\text { Mean Difference } \\
\text { IV, Fixed, } 95 \% \mathrm{CI}\end{array}$}} & \\
\hline & Mean & SD & Total & Mean & SD & Total & Weight & IV. Fixed, $95 \% \mathrm{Cl}$ & & & & \\
\hline Chen QB et al.,2012 & 0.46 & 0.25 & 20 & 3.57 & 2.4 & 30 & $1.0 \%$ & $-3.11[-3.98,-2.24]$ & & & & \\
\hline Duan CX et al.,2014 & 0.49 & 0.24 & 80 & 2.41 & 1.78 & 100 & $5.8 \%$ & $-1.92[-2.27,-1.57]$ & & - & & \\
\hline Hao WM et al.,2015 & 0.74 & 0.69 & 30 & 2.72 & 1.33 & 36 & $2.9 \%$ & $-1.98[-2.48,-1.48]$ & & - & & \\
\hline Huang $\mathrm{H}$ et al.,2011 & 0.3 & 0.08 & 30 & 1.67 & 0.9 & 100 & $22.6 \%$ & $-1.37[-1.55,-1.19]$ & & $=$ & & \\
\hline Huang J et al.,2014 & 0.85 & 0.14 & 33 & 5.15 & 1.65 & 65 & $4.4 \%$ & $-4.30[-4.70,-3.90]$ & - & & & \\
\hline Jiang AK et al.,2018 & 0.41 & 0.22 & 125 & 3.62 & 1.64 & 125 & $8.6 \%$ & $-3.21[-3.50,-2.92]$ & - & & & \\
\hline Jiang MJ et al.,2013 & 0.6 & 0.41 & 50 & 2.51 & 1.61 & 73 & $4.8 \%$ & $-1.91[-2.30,-1.52]$ & & - & & \\
\hline Li B et al., 2012 & 0.51 & 0.3 & 35 & 2.68 & 1.52 & 90 & $6.7 \%$ & $-2.17[-2.50,-1.84]$ & & - & & \\
\hline Li XF et al., 2016 & 0.35 & 0.06 & 50 & 5.78 & 3.92 & 92 & $1.1 \%$ & $-5.43[-6.23,-4.63]$ & & & & \\
\hline LiXQ et al.,2016 & 0.53 & 0.46 & 50 & 2.02 & 1.88 & 42 & $2.1 \%$ & $-1.49[-2.07,-0.91]$ & & & & \\
\hline Liao HY et al.,2014 & 0.3 & 0.08 & 42 & 5.68 & 2.52 & 90 & $2.7 \%$ & $-5.38[-5.90,-4.86]$ & - & & & \\
\hline Qin ZL et al..,2017 & 0.54 & 0.42 & 100 & 1.52 & 1.53 & 104 & $7.7 \%$ & $-0.98[-1.29,-0.67]$ & & 一 & & \\
\hline Shan Z et al.,2013 & 0.82 & 0.09 & 50 & 2.15 & 0.97 & 30 & $6.0 \%$ & $-1.33[-1.68,-0.98]$ & & - & & \\
\hline Tao XJ et al., 2012 & 0.72 & 0.32 & 48 & 2.96 & 2.08 & 69 & $2.9 \%$ & $-2.24[-2.74,-1.74]$ & & - & & \\
\hline Xie GQ et al.,2013 & 0.4 & 0.06 & 32 & 2.02 & 0.98 & 34 & $6.6 \%$ & $-1.62[-1.95,-1.29]$ & & - & & \\
\hline Yuan $Z Y$ et al.,2010 & 0.7 & 0.2 & 14 & 2.14 & 2.08 & 48 & $2.0 \%$ & $-1.44[-2.04,-0.84]$ & & $\longrightarrow$ & & \\
\hline Zhang $L$ et al., 2020 & 0.61 & 0.64 & 20 & 2.59 & 1.21 & 70 & $4.5 \%$ & $-1.98[-2.38,-1.58]$ & & - & & \\
\hline Zhang ZJ et al., 2014 & 0.83 & 0.39 & 161 & 1.41 & 1.25 & 65 & $7.5 \%$ & $-0.58[-0.89,-0.27]$ & & 一 & & \\
\hline Total $(95 \% \mathrm{Cl})$ & & & 970 & & & 1263 & $100.0 \%$ & $-1.94[-2.02,-1.85]$ & & 1 & & \\
\hline \multicolumn{7}{|c|}{$\begin{array}{l}\text { Heterogeneity: } C h i^{2}=626.84, d f=17(P<0.00001) ; I^{2}=97 \% \\
\text { Test for overall effect: } Z=44.67(P<0.00001)\end{array}$} & & & $\frac{1}{-4}$ & $\begin{array}{l}1 \\
-2 \\
\text { Healthy }\end{array}$ & y Malignar & \\
\hline
\end{tabular}

Figure 2A: Forest plots of STK1p levels in healthy controls and breast malignant tumor patients. 
STK1p Level of Breast Malignant Patients Compared to Breast Benign Tumor Patients

Of the 25 studies collected in this meta-analysis, 16 studies were used to examine the difference between breast malignant patients and benign breast disease patients (Figures 2B \& 3A). A total of 1,203 breast malignancy patients and 812 benign disease cases were included in this analysis. Significant differences were examined between the two groups after the heterogeneity test $\left(\mathrm{p}<0.00001, \mathrm{I}^{2}=96 \%\right)$. Therefore, a random-effect model was employed to analyze the effect of the merging. The results showed that there was a significant difference between the two groups (MD $=-1.70,95 \%$ CI $(-1.85 \sim-1.55), \mathrm{p}<0.00001)$. Furthermore, the STK1p level in the breast malignant patients $(3.00 \pm 2.19 \mathrm{pM})$ was significantly higher than that in the benign breast disease patients $(0.96 \pm 0.51 \mathrm{pM})$ (Figure 3A).

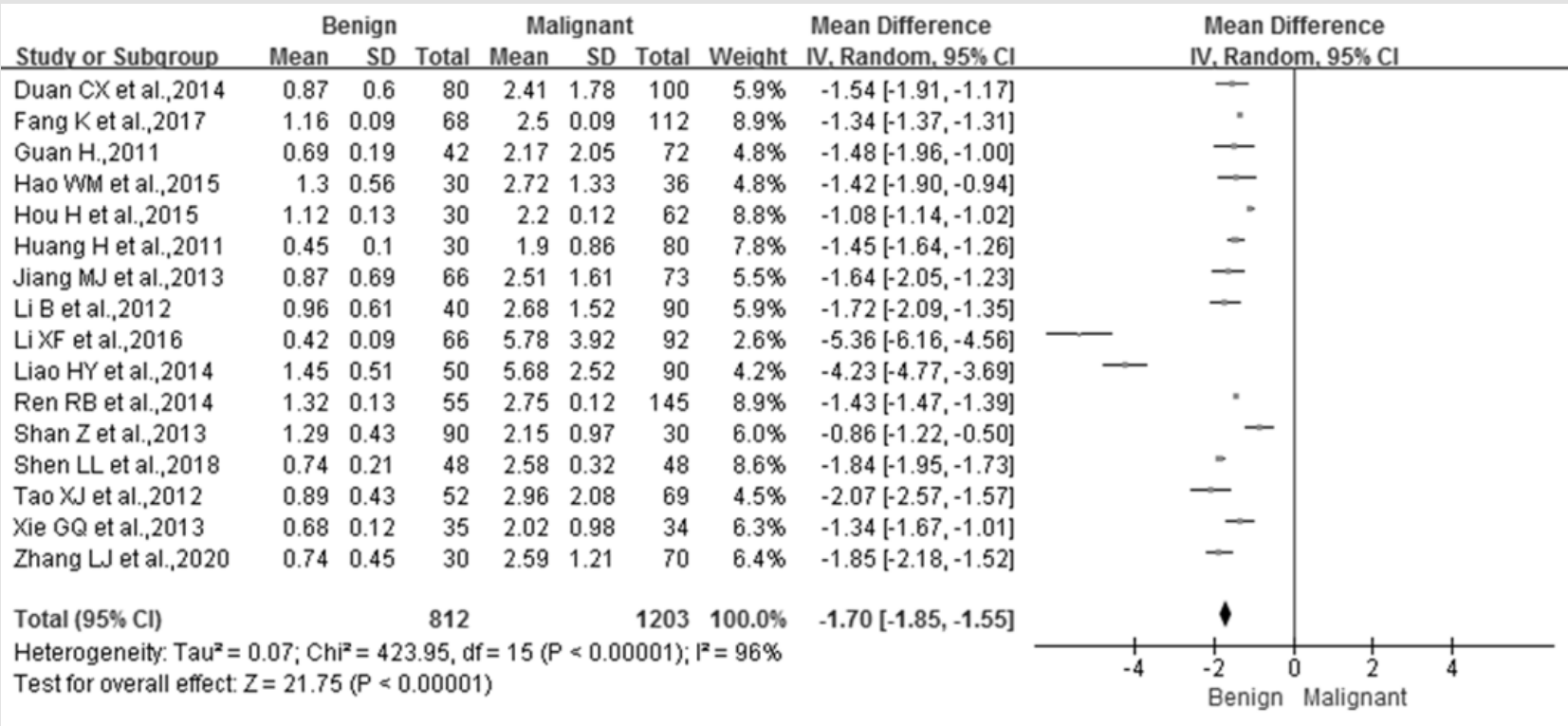

Figure 2B: Forest plots of breast benign tumor patients and breast malignant tumor patients.

\section{STK1p Level of Breast Benign Tumor Patients Compared} to Healthy Control Group

Of the 25 studies collected in this meta-analysis, 11 studies were used to assess the difference between the breast benign disease patients and the healthy individuals (Figures 2C \& 3A). A total of 569 benign disease cases and 467 healthy controls were included in the analysis. Significant differences were examined between the two groups after the heterogeneity test $(\mathrm{p}<0.00001$, $\left.I^{2}=97 \%\right)$. Therefore, a random-effect model was employed to analyze the effect of the merging. The results showed that there was a significant difference between the two groups (MD $=-0.37,95 \%$ CI $(-0.50 \sim-0.23), \mathrm{p}<0.00001)$. Furthermore, the STK1p level in the breast benign patients $(0.96 \pm 0.51 \mathrm{pM})$ was significantly higher than that in the healthy individuals $(0.58 \pm 0.37 \mathrm{pM})$ (Figure $3 \mathrm{~A})$.

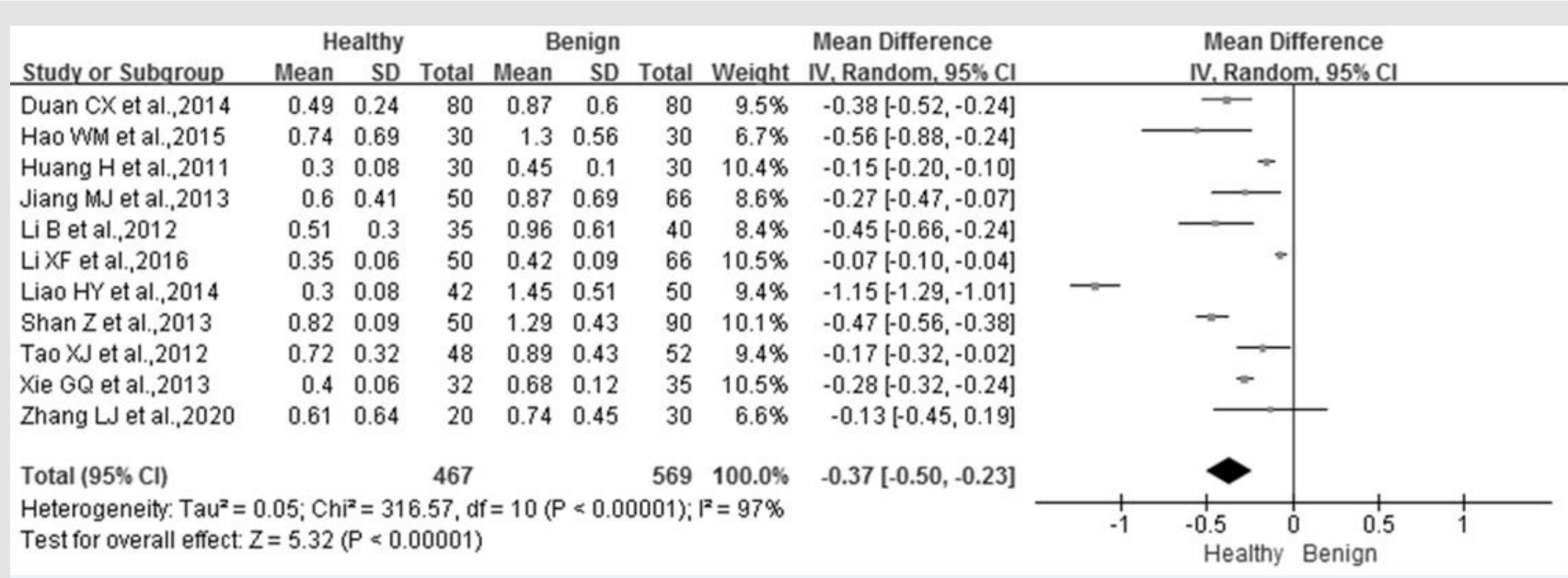

Figure 2C: Forest plots of healthy controls and breast benign tumor patients. 
STK1p Level in Breast Malignant Patients Before and After Surgery Therapy

Of the 25 studies used in this meta-study, 6 studies were included to assess the changes of STK1p concentration before and about one month after surgery therapy. Figure 2D presents the forest plots of the six studies. Heterogeneity test results showed that the $\mathrm{p}$-value was 0.0004 and the $\mathrm{I}^{2}=77 \%$. Therefore, a random- effect model was used to examine the effect of the merging. The results indicated that a statistical significance $(M D=0.98,95 \%$ CI $(0.44-1.52), p=0.0004)$ was found between before and about one month after surgery. Compared to the level before surgery, the STK1p level after surgery treatment significantly declined. The level of STK1p decreased by 30.6\% after surgery therapy (Figure 3B).

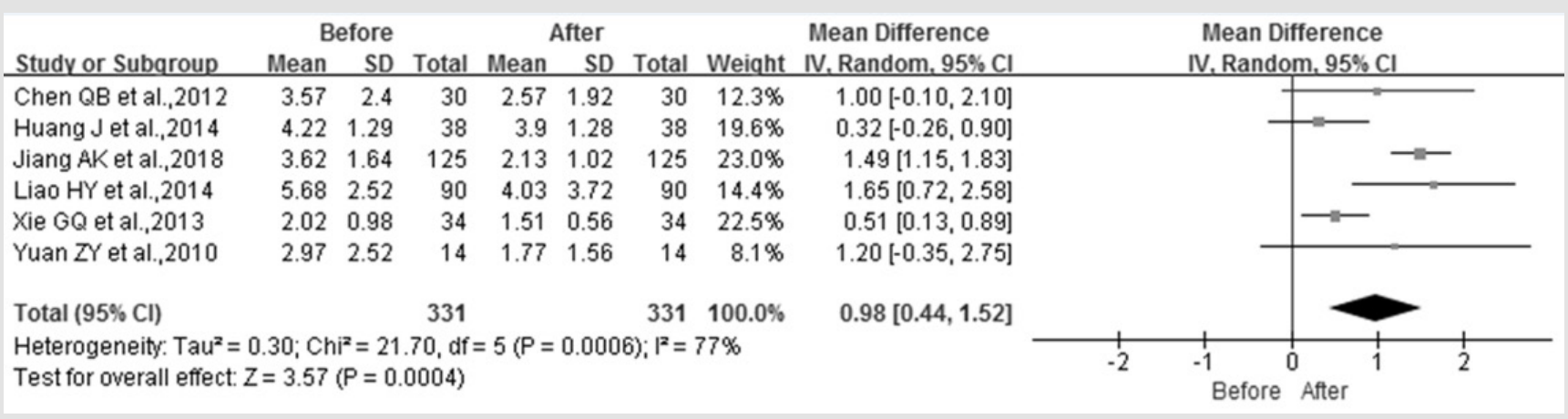

Figure 2D: Forest plots of healthy controls and breast benign tumor patients.
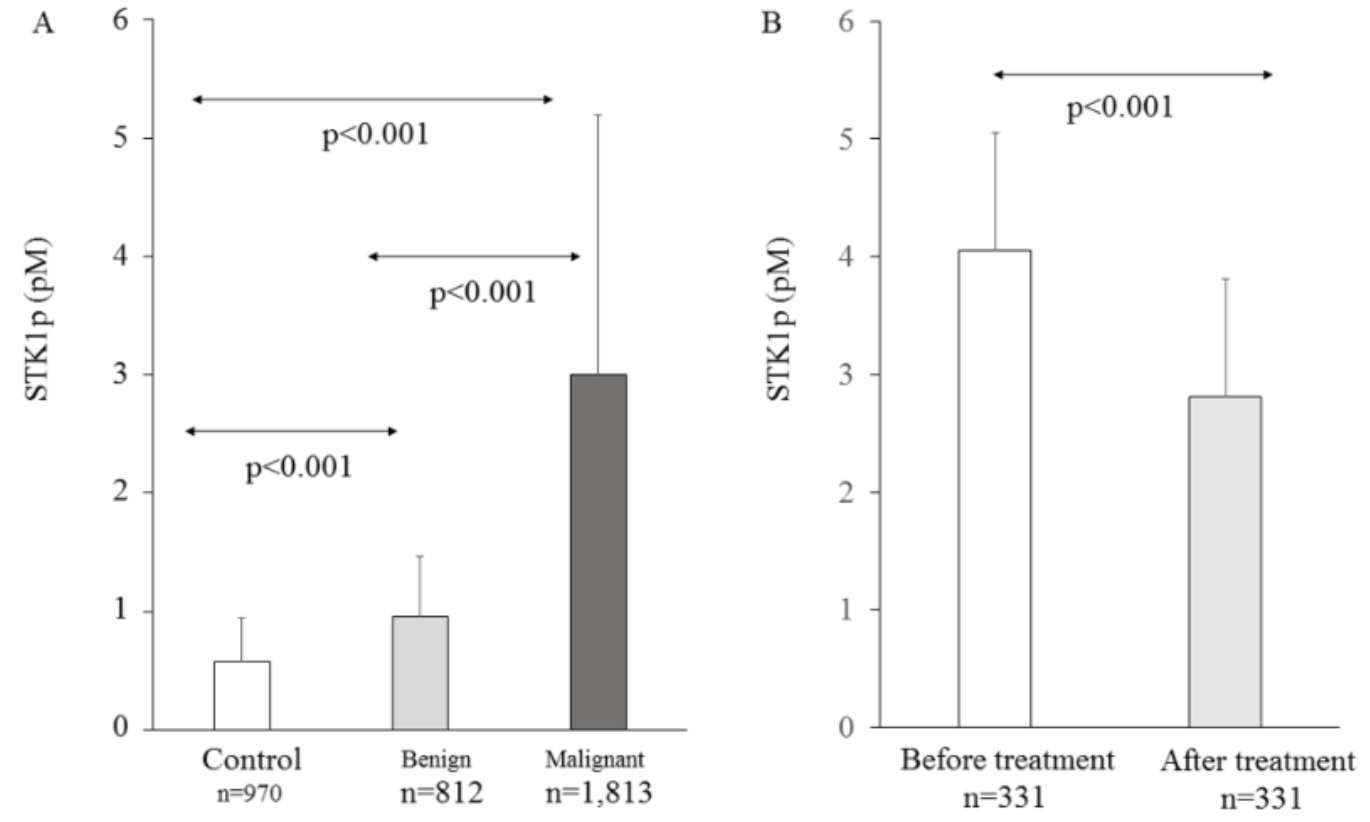

Figure 3:

A. Comparison of STK1 levels among healthy subjects, patients with benign and malignant tumor.

B. Comparison of STK1 levels before and about one month after surgery treatment in breast cancer patients.

\section{Sensitivity Analysis}

Sensitivity analyses were performed to evaluate the effects of excluding any individual study. The influence plots were presented in Figure 4 between the healthy and breast malignant group (Figure $4 \mathrm{~A}$ ), between breast benign disease and malignant group (Figure
4B), between healthy and breast benign disease group (Figure 4C), and between before and after surgery about one-month-group (Figure 4D). By exclusion of 1 literature at a time in turns, the results demonstrated that the remaining literatures did not substantially change in each comparison group. 


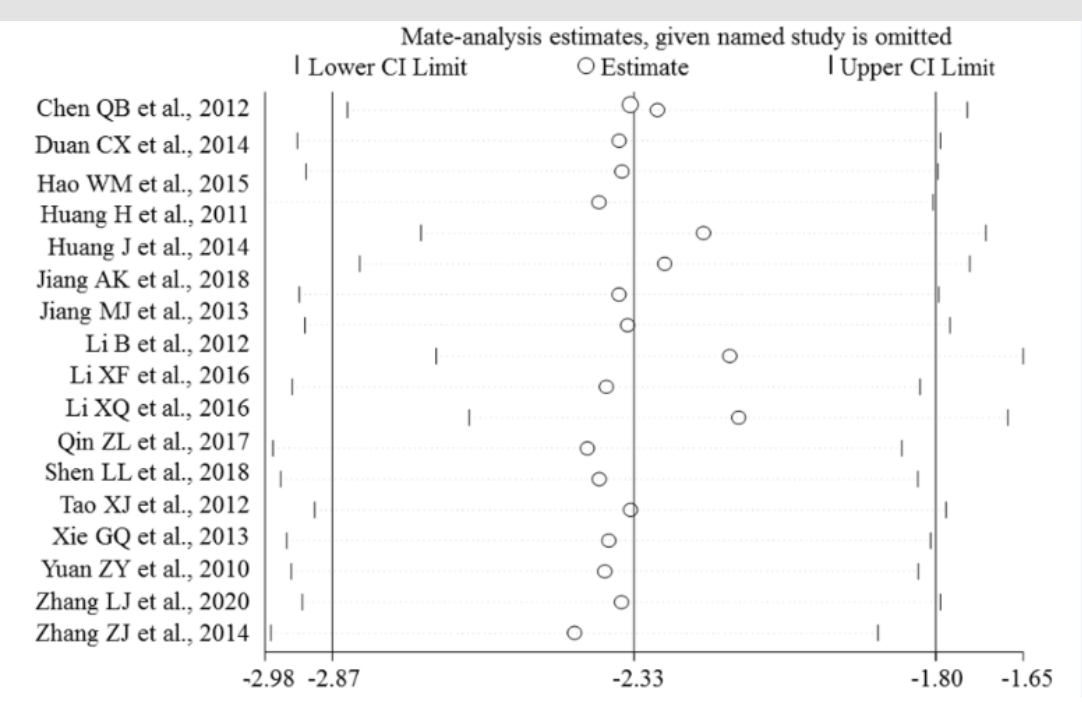

Figure 4A: Plots of the sensitivity between the healthy group and breast malignant tumor group.

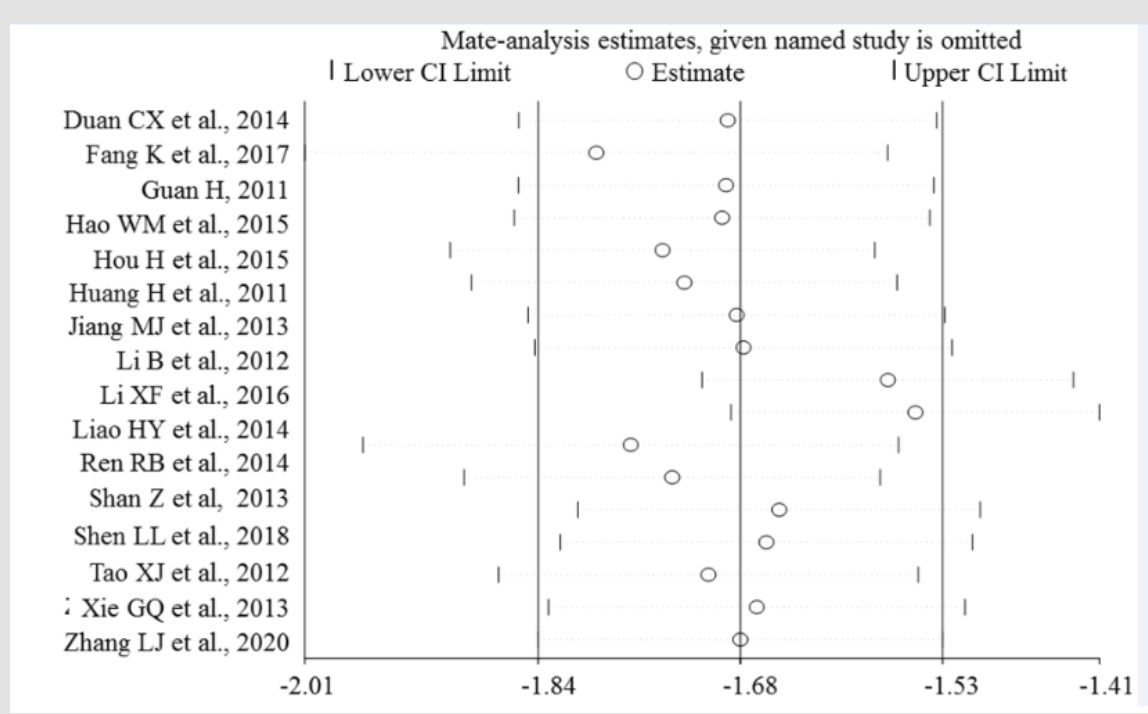

Figure 4B: Plots of the sensitivity between benign group and breast malignant tumor group.

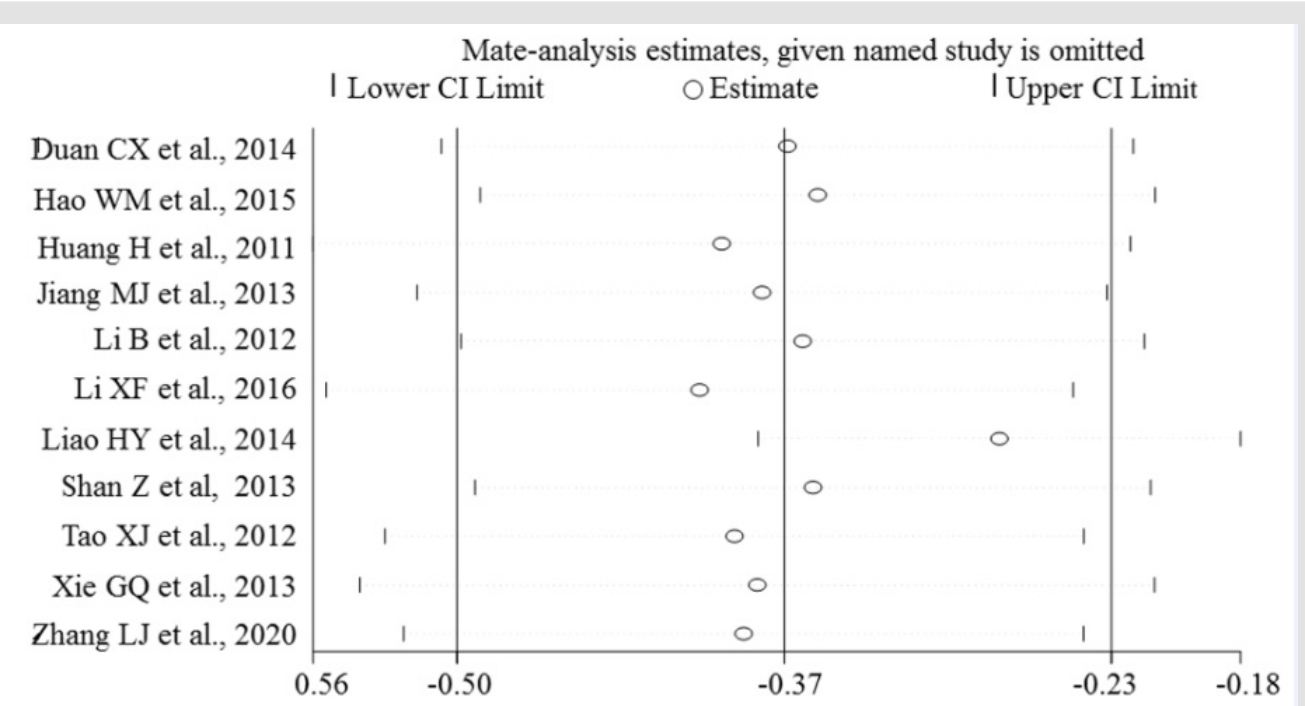

Figure 4C: Plots of the sensitivity between healthy controls and breast benign tumor patients. 


\section{Mate-analysis estimates, given named study is omitted \\ I Lower CI Limit \\ OEstimate \\ I Upper CI Limit}

Chen QB et al., 2012

Huang J et al., 2014

Jiang AK et al., 2018 ,

Liao HY et al., 2014

Xie GQ et al., 2013

Yuan ZY et al., 2010

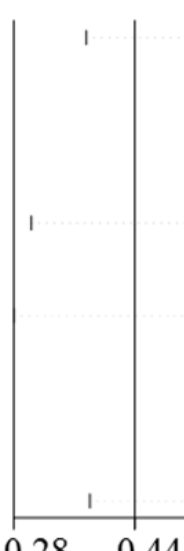

$0.28 \quad 0.44$

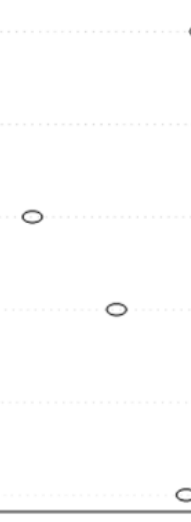

0.99

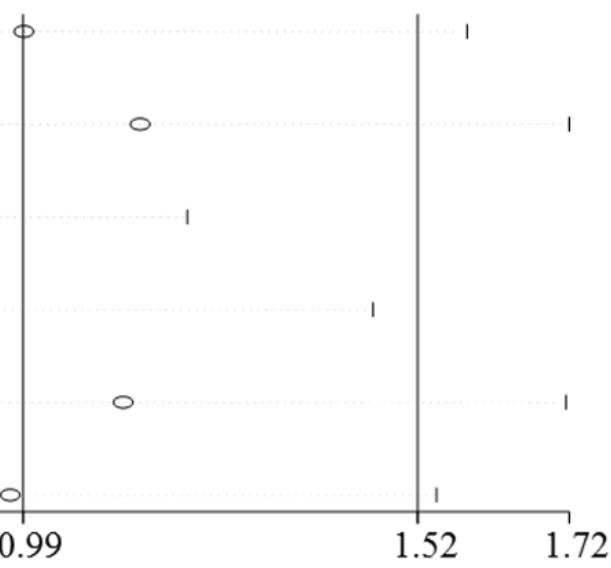

Figure 4D: Plots of the sensitivity before and about one month after surgery treatment in breast cancer patients.

\section{Publication Bias}

Table 2 presented the results of NOS quality assessment in which all NOS scores were higher than 5 points. Egger's linear regression tests were conducted to examine the potential publication bias. The results in Table 3 showed that all p-values for the bias were > 0.05 , which indicated that no significant bias was identified among publications in this meta-analysis.

Table 2: Literature quality evaluation by Newcastle-Ottawa Scale Document Quality Assessment Scale (NOS).

\begin{tabular}{|c|c|c|c|c|c|c|c|c|}
\hline $\begin{array}{l}\text { Author and } \\
\text { issuing time }\end{array}$ & $\begin{array}{l}\text { The } \\
\text { definition } \\
\text { adequate }\end{array}$ & $\begin{array}{c}\text { Representativeness } \\
\text { of the cases }\end{array}$ & $\begin{array}{l}\text { Section } \\
\text { Selection of } \\
\text { controls }\end{array}$ & $\begin{array}{l}\text { Definition } \\
\text { of controls }\end{array}$ & $\begin{array}{l}\text { Comparability } \\
\text { of cases and } \\
\text { controls on } \\
\text { the basis of } \\
\text { the design and } \\
\text { analysis }\end{array}$ & $\begin{array}{l}\text { Ascertainment } \\
\text { of exposure }\end{array}$ & $\begin{array}{l}\text { Exposure same } \\
\text { method of } \\
\text { ascertainment } \\
\text { for cases and } \\
\text { controls }\end{array}$ & $\begin{array}{l}\text { Non- } \\
\text { response rate }\end{array}$ \\
\hline $\begin{array}{c}\text { Chen QB et al. } \\
{[16]}\end{array}$ & $*$ & $*$ & & $*$ & $*$ & $*$ & $*$ & $*$ \\
\hline $\begin{array}{c}\text { Duan CX et al. } \\
{[22]}\end{array}$ & $*$ & * & & $*$ & * & $*$ & * & * \\
\hline $\begin{array}{c}\text { Fang K et al., } \\
{[31]}\end{array}$ & $*$ & $*$ & & $*$ & $* *$ & $*$ & * & * \\
\hline Guan H, [14] & $*$ & * & & & * & * & * & $*$ \\
\hline $\begin{array}{c}\text { Hao WM et al. } \\
{[27]}\end{array}$ & $*$ & $*$ & $*$ & $*$ & * & $*$ & * & * \\
\hline $\begin{array}{l}\text { Hou H et al. } \\
\text { [28] }\end{array}$ & $*$ & $*$ & & & $*$ & $*$ & $*$ & $*$ \\
\hline $\begin{array}{l}\text { Huang } \mathrm{H} \text { et al. } \\
\text { [15] }\end{array}$ & $*$ & $*$ & $*$ & $*$ & $*$ & $*$ & * & $*$ \\
\hline $\begin{array}{l}\text { Huang J et al. } \\
\text { [23] }\end{array}$ & $*$ & * & * & $*$ & * & * & * & * \\
\hline $\begin{array}{c}\text { Jiang AK et al. } \\
\text { [35] }\end{array}$ & $*$ & $*$ & $*$ & $*$ & $* *$ & $*$ & $*$ & $*$ \\
\hline $\begin{array}{c}\text { Jiang MJ et al. } \\
{[19]}\end{array}$ & $*$ & * & $*$ & $*$ & * & $*$ & $*$ & $*$ \\
\hline Li B et al. [17] & $*$ & $*$ & & $*$ & $*$ & $*$ & $*$ & $*$ \\
\hline $\begin{array}{l}\text { Li XF et al. } \\
\quad[30]\end{array}$ & $*$ & $*$ & $*$ & $*$ & ** & $*$ & * & $*$ \\
\hline $\begin{array}{l}\text { Li XQ et al. } \\
\text { [29] }\end{array}$ & * & $*$ & & $*$ & ** & & $*$ & \\
\hline $\begin{array}{l}\text { Liao HY et al. } \\
\text { [24] }\end{array}$ & $*$ & $*$ & & & $*$ & $*$ & $*$ & $*$ \\
\hline
\end{tabular}




\begin{tabular}{|c|c|c|c|c|c|c|c|c|}
\hline $\begin{array}{l}\text { Nong L et al. } \\
{[36]}\end{array}$ & $*$ & $*$ & & & $* *$ & * & * & * \\
\hline $\begin{array}{l}\text { Qin ZL et al. } \\
{[32]}\end{array}$ & * & $*$ & $*$ & * & ** & * & * & * \\
\hline $\begin{array}{c}\text { Ren RB et al. } \\
{[25]}\end{array}$ & $*$ & $*$ & $*$ & $*$ & $*$ & $*$ & $*$ & * \\
\hline $\begin{array}{c}\text { Shan Z et al } \\
{[20]}\end{array}$ & $*$ & * & & * & $*$ & $*$ & * & * \\
\hline $\begin{array}{c}\text { Shen LL et al. } \\
\text { [34] }\end{array}$ & $*$ & $*$ & & $*$ & $* *$ & $*$ & * & * \\
\hline $\begin{array}{c}\text { Tao XJ et al. } \\
{[18]}\end{array}$ & $*$ & $*$ & $*$ & $*$ & $*$ & $*$ & $*$ & * \\
\hline $\begin{array}{c}\text { Xie GQ et al. } \\
{[21]}\end{array}$ & $*$ & $*$ & $*$ & $*$ & $*$ & $*$ & * & * \\
\hline $\begin{array}{c}\text { Yuan ZY et al. } \\
{[13]}\end{array}$ & $*$ & $*$ & & $*$ & $*$ & $*$ & $*$ & * \\
\hline Zhang HZ [33] & $*$ & $*$ & & & $*$ & * & $*$ & * \\
\hline $\begin{array}{c}\text { Zhang LJ et al. } \\
\text { [37] }\end{array}$ & $*$ & $*$ & $*$ & * & $* *$ & * & $*$ & * \\
\hline $\begin{array}{c}\text { Zhang ZJ et al. } \\
{[26]}\end{array}$ & $*$ & $*$ & & & $*$ & $*$ & * & $*$ \\
\hline
\end{tabular}

Table 3: Egger's tests for the assessment of publication bias.

\begin{tabular}{|c|c|c|c|c|c|}
\hline Standard effect & Coefficient & Standard error & T value & $p>|t|$ & $95 \% \mathrm{CI}$ \\
\hline \multicolumn{6}{|c|}{ Healthy vs. Malignant } \\
\hline Slope & -5.589 & 2.009 & -2.78 & 0.013 & -9.850 to -1.329 \\
\hline Bias & -0.794 & 0.607 & -1.31 & 0.209 & -2.083 to 0.494 \\
\hline \multicolumn{6}{|c|}{ Benign vs. Malignant } \\
\hline Slope & -5.997 & 1.532 & -3.91 & 0.002 & -9.283 to -2.711 \\
\hline Bias & -0.685 & 0.346 & -1.98 & 0.067 & -1.427 to 0.056 \\
\hline \multicolumn{6}{|c|}{ Healthy vs. Benign } \\
\hline Slope & -1.494 & 1.999 & -0.75 & 0.474 & -6.017 to 3.029 \\
\hline Bias & -0.253 & 0.181 & -1.40 & 0.195 & -0.661 to 0.156 \\
\hline \multicolumn{6}{|c|}{ Before vs. After treatment } \\
\hline Slope & 0.629 & 1.421 & 0.44 & 0.681 & -3.317 to 4.576 \\
\hline Bias & 0.763 & 0.558 & 1.37 & 0.243 & -0.785 to 2.312 \\
\hline
\end{tabular}

\section{Discussion}

A meta-analysis is to systematically analyze data from several different studies in order to synthesize the results based on a larger number of samples [38]. In the present study, the meta-analysis results indicated that STK1p was a useful and reliable biomarker in distinguishing breast malignancy risk from non-malignancies and monitoring the treatment response to surgery therapy in breast malignant patients. Furthermore, no significant bias was found in this meta-analysis. Breast cancer is a relatively high incidence rate of malignancy in women. Although the continuous development of B-ultrasound, mammography examination and other detection technology has improved the early diagnosis rate of breast cancer, the current early malignancy detection technologies still have certain limitations. In addition, some breast cancer patients in early stage lack of specific clinical symptoms. It is difficult to detect many small lesions in early breast cancer.
When patients have obvious clinical symptoms, most of them can only be treated by radical mastectomy. At the same time, most breast cancer patients are not willing to accept traumatic surgical treatment, and are willing to take conservative treatment, which requires clinicians to be able to diagnose breast lesions as early as possible. At present, CA153 is widely used in the serological detection of breast cancer, but the sensitivity and accuracy are still low [39]. STK1p is considered to be a new potential biomarker for the risk detection of early breast precancerous lesions and malignant tumors in female population. The results of the present study indicated that the STK1p concentration in breast patients was significantly higher than that in healthy individuals, also significantly higher than that in benign breast disease groups which provides a chance to distinguish them. These findings suggest that STK1p concentration can be used as an early risk warning indicator for dynamic development of breast cancer from an early 
stage. Measuring STK1p concentration would be a supplementary approach to assist assessing malignancy risk of benign diseases in early stage. Similar results were reported in other published studies where individuals with STK1 $\mathrm{p}$-values $>2.0 \mathrm{pM}$ were found to have a 3-5 times higher risk to develop a malignancy based on a large scale health screening study $(n=35,365)$ [40]. The results suggest that the abnormal proliferation of tumor cells could be detected sensitively by monitoring the STK1p concentration level.

In addition, the STK1p level after surgery therapy was significantly lower compared to the level before surgery. The results suggested that STK1p has the potential to become a useful monitoring index in evaluating the treatment responses in breast cancer patients. According to prior studies [8,9], the halflife of STK1p after treatment may differ depending on different types of therapy approaches, for example extensive open surgery, minimally invasive surgery or chemotherapy, and also depending on different types of malignant tumors. In a primary bladder carcinoma patients study, the half-life of STK1p was six days after cystectomy by electrosurgical technique [41]. In another similar study, the STK1p level in patients with non-Hodgkin's lymphoma during chemotherapy increased to $127 \%$ during the first few days, and then declined by $79 \%$ one month after the chemotherapy [42]. In this study, the meta-analysis results indicated that the STK1p level after surgery treatment significantly declined by $30.6 \%$ after surgery therapy. These findings suggest that the half-life of STK1p protein may be an important tool for monitoring the treatment responses in breast cancer patients.

The clinical significance of the ECL dot-blot serum TK1 immunoassay in regular health examination for malignant diseases have been verified by large-scale population research [43]. In addition, in a long-term follow-up study of 120 breast cancer patients at the Karolinska University Hospital/Karolinska Institute in Sweden, it was found that the expression of STK1p three months after the operation can effectively evaluate the prognosis and survival of patients, and thus be used as an independent prognostic factor for breast cancer patients [7]. A recent study also showed that STK1p has a good evaluation value in the prognosis, survival and recurrence of triple negative breast cancer [44]. However, due to the small amount of data, there is still need to collect a large number of triple negative breast cancer to valid these results. Meta-analysis is an observational study, which has some limitations in nature. During assessing publication bias, the subjective influence of the researchers may affect the conclusion. Regarding the limitation, the Egger's test was employed to evaluate the effects of publication bias in order to minimize the deficiency [45]. In conclusion, this metaanalysis indicated that the level of STK1p in breast cancer patients was significantly higher than that in benign disease group and the healthy control group. The level of STK1p in breast cancer patients decreased significantly after being treated. Thus, STK1p would be a useful biomarker for breast benign and malignant tumor risk assessment and treatment response assessment.

\section{Conflict of interest}

None

\section{References}

1. Torre LA, Bray F, Siegel RL, Ferlay J, Lortet Tieulent J, et al. (2015) Global Cancer Statistics, 2012. CA A Cancer Journal for Clinicians 65(2): 87-108.

2. (2010) Report of the third retrospective sampling survey on causes of death in China. China Union Medical University press. Beijing, China pp. 120-131.

3. Sherley JL, Kelly TJ (1988) Regulation of human thymidine kinase during the cell cycle. The Journal of Biological Chemistry 263: 8350-8358.

4. Zhou J, He E, Skog S (2013) The proliferation marker thymidine kinase 1 in clinical use. Molecular and Clinical Oncology 1: 18-28.

5. Jagarlamudi KK, Shaw M (2018) Thymidine kinase 1 as a tumor biomarker: technical advances offer new potential to an old biomarker. Biomarkers in Medicine 12(9): 1035-1048.

6. Chen F, Tang L, Xia T, He E, Hu G, et al. (2013) Serum thymidine kinase 1 levels predict cancer-free survival following neoadjuvant, surgical and adjuvant treatment of patients with locally advanced breast cancer. Molecular and Clinical Oncology 1(5): 894-902.

7. He Q Fornander T, Johansson H, Johansson U, Hu GZ, et al. (2006) Thymidine kinase 1 in serum predicts increased risk of distant or locoregional recurrence following surgery in patients with early breast cancer. Anticancer Research 26(6C): 4753-4759.

8. Zou L, Zhang PG, Zou S, Li Y, He Q (2002) The half-time of cytosolic thymidine kinase in serum by ECL dot blot: a potential marker for monitoring the response to surgery of patients with gastric cancer. The International Journal of Biological Markers 17: 135-140.

9. Lou X, Zhou J, Ma H, Xu S, He E, et al. (2017) The Half-Life of Serum Thymidine Kinase 1 Concentration Is an Important Tool for Monitoring Surgical Response in Patients with Lung Cancer: A Meta-Analysis Genetic Testing and Molecular Biomarkers 21(8): 471-478.

10. Skog S, He E, Haghdoost S (2017) Prevention and Early Detection of Human Tumor. LAP LAMBERT Academic Publishing, Republic of Moldova.

11. Feng Y, Spezia M, Huang S, Yuan C, Zeng Z, et al. (2018) Breast cancer development and progression: Risk factors, cancer stem cells, signaling pathways, genomics, and molecular pathogenesis. Genes and Diseases 5(2): 77-106.

12. Elston CW, Ellis IO (1991) Pathological prognostic factors in breast cancer. I. The value of histological grade in breast cancer: experience from a large study with long-term follow-up. Histopathology 19(5): 403410.

13. Yuan ZY, Liu XA, Ling LJ, Zhao Y, Wang S (2010) The significance of serum thymidine kinase 1 on assistant diagnosis and evaluation of chemotherapy effect on breast cancer patients operated. Acta Universitatis Medicinalis Nanjing 30(7): 1002-1004.

14. Guan H (2011) Predictive value of serum/cytoplasmic thymidine kinase 1 level in the diagnosis and prognosis of breast cancer. Journal of Hainan Medical University 17: 728-730.

15. Huang H, Luo YL (2011) The role of serum thymidine kinase 1 levels in the postoperative evaluation of curative effect of breast cancer Laboratory Medicine 26(2): 79-81.

16. Chen QB, Li CC, Zhao R, Dai Y, Chen QJ (2012) The application study on serum thymidine kinase 1 level changes for diagnosis and therapy of breast cancer. Journal of Practical Medicine 28(05): 728-730. 
17. Li B, Cao JX, Cheng HX (2012) The clinical significance and the change of serum TK1 level in breast carcinoma patients. J of Radioimmunology 25(5): 587-588.

18. Tao XJ, Chen GM, Feng XH, Sun YF (2012) Clinical value of combined detection of serum TK1, TPS and CA15-3 in diagnosis of breast cancer International Journal of Laboratory Medicine 33(16): 1943-1944.

19. Jiang MJ, Fan WF, Hang ZZ, Weng B, Che SS (2013) Clinical value of carcinoma antigen 153, thymidine kianse 1 and tumor specific growth factor detection in breast cancer. Progress in Modern Biomedicine 13(27): 5315-5318.

20. Shan Z, Sun XW (2013) The clinical analysis for the change of serum TK1 in breast carcinoma patients. World Latest Medicine Information (1) 265-266.

21. Xie GQ Xiao HL, Shao YM (2013) Clinical value of determination on serum IL-2/MMP-9,TK1 and sFas levels both before and after operation in patients with Breast cancer. J of Radioimmunology 26(4): 396-399.

22. Duan CX, Hao YM, Chen LX (2014) The Changes and Clinical Values of Serum TK1 and CA15-3 Levels in Patients with Breast Cancer. China \& Foreign Medical Treatment 33(35): 1-2.

23. Huang J, Tan XH, Tang Y (2014) Expression of thymidine kinase 1 in serum of patients with breast carcinoma and its clinical significance. IMHGN 20(24): 3726-3728.

24. Liao HY (2014) The evaluation of serum TK1, CA15-3 and CEA in breast cancer patients with chemotherapy. J Shanxi Med Univ 45(2): 123-125.

25. Ren RB, Xu Cheng, Li YF, Jin YN, He JR (2014) Expression of serum TK1 in human breast tumor and its clinical significance. China Oncology 24(1): 41-45.

26. Zhang ZJ, Zheng YP, Lin YF, Mei XQ (2014) Clinical detecting application of TK1 in the diagnosis of common malignant tumors. International Journal of Laboratory Medicine (19): 2636-2637.

27. Hao WM, Xia HL (2015) The clinical significance of serum TK1 level used in early detection of breast carcinoma. The Journal of Practical Medicine (5): 774-776.

28. Hou H, Chen YK, Li ZF, Wang BG (2015) The expression of TK1 in benign and malignant breast tumors. Journal of General Surgery for Clinicians (4): 12-14.

29. Li XQ, Zou ST, He C, Yu J, Wu FY, et al. (2016). Expression and Clinical Significance of Serum Thymidine Kinase 1 in Breast Cancer. Chin J Hemorh 26(1): 68-69.

30. Liu XF, Xu HY, Yin SJ, Zhang YL (2016) Changes and clinical significance of serum TK, CA153 CEA in breast cancer patients. Int J Lab Med 37(17): 2392-2393.

31. Fang K, Hou H, Wang QT, Wang CP, Xu P, et al. (2017) Expression of TK in benign and malignant tumors. Chin J Endocr Surg 11(05): 377-379.
32. Qin ZL, Zeng JY, Xing YL, Zhang NH, Niu IZ (2017) Changes of serum TK1 Level in breast cancer patients with resection after ozone therapy. Modern Oncology 25(18): 2915-2918.

33. Zhang HZ (2017) Evaluation of serum TK1, CA15-3 and CEA levels in the treatment of breast cancer. China Health Care \& Nutrition 10: 62

34. Shen LL, Huang P (2018) The diagnostic value of serum Angptl2 TK1 Levels combined With color Doppler ultrasonography for mammary cancer. Journal Of Guangxi Medical University 35(11): 1539-1542.

35. Jiang AK, Yan CJ (2018) Changes in levels of serum CYFRA21-1, TK1 and CA15-3 in patients undergoing modified radical mastectomy for breast cancer and their correlation with postoperative recurrence. Translational Medicine Journal 7(02): 79-81.

36. Nong L, Jia Y, Wang H, Liu Y, Tan A, et al. (2019) Correlation between serum thymidine kinase 1 and HER-2 positive advanced breast cancer. Journal of Modern Medicine \& Health 35: 12-15.

37. Zhang L, Wang X, Liu J (2020) Relationship between the expression of serum TPS and TK1 and pathological characteristics in breast cancer Medical \& Pharmaceutical Journal of Chinese People's Liberation Army 32: 32-35.

38. Cooper HM, Hedges LV, Valentine J (2009) The handbook of research synthesis and meta-analysis. Russell Sage Foundation. New York USA.

39. Chen Z, Zhou F, Fu Y, Xu Y, Tian Z (1998) Immunoradiometric analysis of tumor marker CA15-3 and its clinical application. Chinese Journal of Oncology 2: 125-128.

40. Chen ZH, Huang SQ, Wang Y, Yang AZ, Wen J, et al. (2011) Serological thymidine kinase 1 is a biomarker for early detection of tumours--a health screening study on 35,365 people, using a sensitive chemiluminescent dot blot assay. Sensors (Basel). 11(12): 11064-80.

41. Zhang J, Jia Q Zou S, Zhang P, Zhang X, et al. (2006) Thymidine kinase 1: a proliferating marker for prognosis and monitoring the outcome of surgery of primary bladder carcinoma patients. Oncology Reports 15: 455-461.

42. Pan ZL, Ji XY, Shi YM, Zhou J, He E, et al. (2010) Serum thymidine kinase 1 concentration as a prognostic factor of chemotherapy-treated nonHodgkin's lymphoma patients. Journal of Cancer Research and Clinical Oncology 136: 1193-1199.

43. Wang Y, Jiang X, Wang S, Yu H, Zhang, et al. (2018) Serological TK1 predict pre-cancer in routine health screenings of 56,178 people. Cancer Biomarkers 22(2): 237-247.

44. Niu Y, Yao Y, Ma X (2016) Expressions and clinical significances of TKl and Ki-67 in triple negative breast cancer. Journal of international oncology 43: 409-413.

45. Egger M, Davey Smith G, Schneider M, Minder C (1997) Bias in metaanalysis detected by a simple, graphical test. British Medical Journal 315: 629-634.
ISSN: 2574-1241

DOI: $10.26717 /$ BJSTR.2020.30.004943

Ailian Hei, Ellen He. Biomed J Sci \& Tech Res

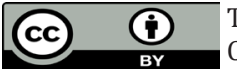

This work is licensed under Creative Commons Attribution 4.0 License

Submission Link: https://biomedres.us/submit-manuscript.php

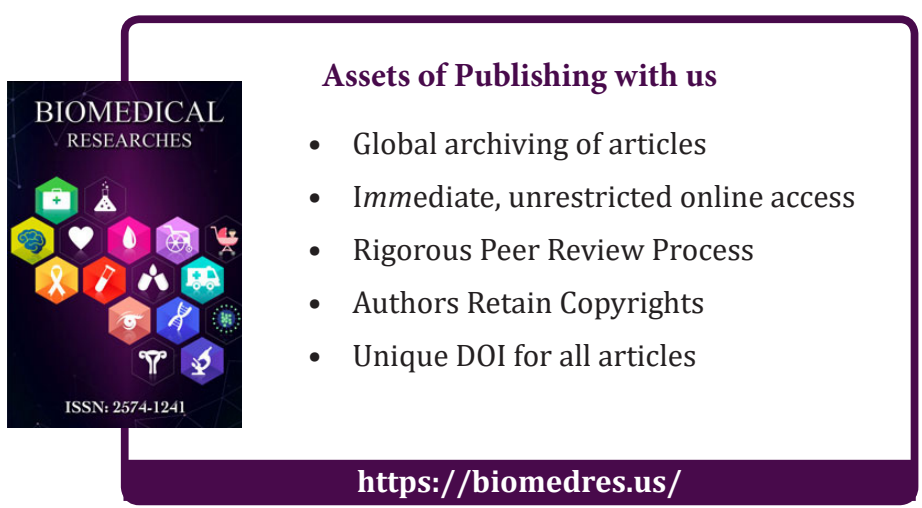

